\title{
Identification Of Prospective Science Teachers' Mathematical-Logical Structures In Reference To Magnetism
}

\author{
İsmail Y1lmaz, Sakarya University, Turkey
}

\begin{abstract}
This paper is a qualitative case study designed to identify prospective science teachers' mathematical-logical structures on the basis of their knowledge and achievement levels in magnetism. The study also made an attempt to reveal the effects of knowledge-level variables and procedural variables, which were considered to be potential factors, on the teachers' knowledge and achievement levels. The participants' knowledge level was represented by the APS score (knowledge-level variable), whereas their achievement level was expressed by the ASS score (achievement level). The prospective teachers' knowledge and achievement levels in mathematical logic were 0.204 and 0.305 , respectively. The knowledge-level variables were given-asked, formula, and operation. On the other hand, the procedural variables consisted of formula knowledge, basic math knowledge, and scientific knowledge. The latter group of variables had the following values, respectively: 0.336, 0.758, and 0.199. The findings indicated that basic math knowledge led the participants to have an achievement level higher than their knowledge level. The other variables had values similar to those of the knowledge and achievement levels.
\end{abstract}

Keywords: Science Teachers' Mathematical-Logical Structures; Teacher's Knowledge and Achievement Levels in Mathematical Logic; Knowledge-Level Variables; Procedural Variables

\section{INTRODUCTION}

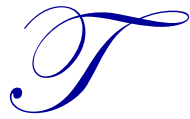

he process of educating and teaching can be divided into different dimensions in reference to particular variables. When the variable is "individuals," the components of the process are learning individuals, teaching individuals, family (e.g., parents), friends, school administrators, and so forth. Undoubtedly, teachers are one of the most important components. As a component, teachers can be classified into two sub-groups: teachers and prospective teachers. Studies on the academic development of prospective teachers are of major importance because they provide immediate feedback on the basis of their results. Accordingly, the present study focuses on the academic development of prospective teachers.

One of the subjects taught within the scope of science education - magnetism - is a significant field of scientific knowledge. In teaching scientific knowledge, it is important to know and develop its type, epistemological structure, semiotic structure, information value, and logical structure. In other words, the quality of knowledge is a significant consideration in teaching scientific knowledge. Educational activities are strongly influenced by teaching methods and techniques. However, the quality of knowledge should be focused more in science education, unlike other disciplines, because the main objective is to teach science.

Attaching importance to the quality of knowledge involves an emphasis on the logic of knowledge. Mathematical logic constitutes the logical structure of science in an adequate manner (Ryall, 1958, p. 1; Gözkan, 2008, pp. 180-185; Heijenoort, 1970, pp. 1-2). Similarly, scientific knowledge often relies on predicate calculus or mathematical logic (McCarthy, 1988; Nilsson \& Fikes, 1970; Bonner \& Kifer, 1993). Furthermore, mathematical 
logic is an instrument for understanding and performing science. It is used for disclosing the nature of scientific theories and forms the basis of scientific logic (Özenli, 1994, p. 35). In other words, mathematical logic is that of scientific knowledge. For all these reasons, it has a prominent place in science education.

One of the objectives of science education is to teach scientific knowledge. Who should be responsible for teaching the logic of this knowledge? At what age and what knowledge level should the logic of knowledge be taught? What epistemological levels should accompany the process of teaching knowledge and logic? Teaching mathematical knowledge may not be the responsibility of science teachers; even so, they should be able to understand the type of scientific knowledge that they are expected to be familiar with and teach. Knowing does not necessarily mean understanding. Mathematical logic gains importance when it is recognized that teachers and prospective teachers should be able to understand what they have to know about and teach. This is because mathematical logic is an instrument for understanding scientific knowledge. In fact, when they want (or are asked) to be a developer of scientific knowledge, it becomes an obligation for them to know about the logical structure of knowledge. In the present study, the prospective teachers' knowledge level in mathematical logic was tested through their knowledge and achievement levels, given that one's knowledge about something can be represented by his/her knowledge and achievement levels (Yılmaz, 2012; Yılmaz \& Yalçın, 2012a, 2012b, 2012C, 2012d). Their knowledge and achievement levels collectively represented their knowledge status.

The purpose of the present study is to identify the logical structures of prospective teachers' scientific knowledge, a significant component in science education. Prospective teachers' logical structures can be revealed at two different levels; namely, knowledge and achievement levels. The most appropriate way of identifying their knowledge and achievement levels in a detailed way is to conduct a qualitative study. For this reason, the present study employed a qualitative method. The data for the study were analyzed through the VDOIHI statistic, which is suitable for identifying knowledge and achievement levels (Y1lmaz, 2011). The VDOIHI statistic enables researchers to evaluate knowledge and achievement levels separately as the APS and ASS scores, respectively. In addition, it allows the interaction between dependent and independent variables to be analyzed in a detailed way. This is another reason the VDOIHI statistic is used in the present study, which needed a detailed analysis of the interaction between dependent (APS and ASS) and independent variables. The present study was focused on prospective teachers' mathematical-logical structures because mathematical logic is not only the logic of scientific knowledge but also an instrument for understanding and performing science.

\section{METHODOLOGY}

In the present study, magnetism, a subject of the course General Physics II, included in the scienceteaching curriculum, was chosen so as to identify the prospective science teachers' mathematical-logical structures as well as the variables that might affect these structures. The reason for basing the study on magnetism is that it is a significant subject in many ways and a clear example of mathematical logic. The prospective science teachers' mathematical-logical structures were identified through their knowledge and achievement levels in magnetism. In other words, the term mathematical-logical structures was used to refer to their knowledge and achievement levels. The stages of problem-solving, which had an influence on the prospective teachers' knowledge and achievement levels in mathematical logic, were accepted as the study variables. The variables that could affect the way mathematical-logical problems were solved were given-asked, formula, and operation. These variables were called knowledge-level variables. They could only affect the participants' achievement level. On the other hand, the variables that could influence not only their achievement level, but also their knowledge level in mathematical logic, were formula knowledge about magnetism, scientific knowledge, and basic math knowledge. These were called procedural variables. In total, the present study examined six variables that could affect the prospective teachers' mathematical-logical structures. This is a qualitative case study comprising of 35 first-grade prospective science teachers who had already learned about magnetism.

The prospective science teachers' mathematical-logical structures were identified through a measurement tool that contained seven items (hereinafter referred to as measurement tool 1 [MT1]). In MT1, a mathematical proposition about magnetism was provided prior to every two questions. For questions that followed the propositions, the participants were provided with formulas for magnetism and asked to comment on whether the formulas satisfied the given propositions. In the last question, a mathematical-logical proposition regarding 
magnetism topics, including an example, was asked. While answering the questions in MT1, the participants were expected to write down the "given-asked" for the question to express explicitly as to how the formula was related to solving the problem and to prove whether the formula satisfied the given proposition. All of these constituted the knowledge-level variables for MT1. The responses to MT1 were graded in reference to the VDOIHI (Y1lmaz, 2011; Yılmaz \& Yalçın, 2011). In the statistic, grading can be carried out in two different ways: 1) In the first, variables are scored after they have been divided into stages and 2) The second way requires one to grade the result (i.e., the solution to the question). In the present study, each response was assigned a $\mathrm{Cb}$ score and the ASS score was calculated based on it. The ASS score was accepted as the participants' achievement level and their knowledge level was comprised of the APS scores in MT1.

The IS, APS, ANS, NAPS, and SS scores (Yılmaz, 2011; Yılmaz \& Yalçın, 2011) were calculated for each knowledge-level variable that had an influence on the prospective science teachers' achievement level. The scores were calculated in three different stages; namely, positive, negative, and neutral, in reference to the comparison between what was written by the participants for the variable when they solved the questions in MT1 and the actual solutions. The scores in the positive, negative, and neutral stages were used to calculate the APS, ANS and NAPS, and IS scores, respectively. The percentage values of the IS, APS, ANS, NAPS, and SS scores for each variable suggested the effect of that variable on the achievement level. In addition, the APS score represented the participants' knowledge level. In this way, the knowledge-level variables could be associated with the achievement level.

The other variables in the prospective teachers' achievement and knowledge levels (structure) were formula knowledge, scientific knowledge, and basic math knowledge. The effect of formula knowledge on the knowledge and achievement levels was revealed through a measurement tool that contained 36 questions about magnetism (hereinafter referred to as measurement tool 2 [MT2]). For these questions, the prospective teachers were provided with a particular formula for magnetism and asked to name it. Each correct naming was assigned one point. This variable represented the formula procedures for MT1; i.e., the scientific physics procedures for MT1. Each question in MT2 was associated with one or more questions in MT1, as the questions in MT2 represented the formula procedures for the questions in MT1. In this way, an attempt was made to determine whether the participants had procedural knowledge to solve the questions in MT1 and to define a variable in their mathematical-logical structures. All the scores obtained from the participants' responses to the questions in MT2 yielded the MT2 score, which revealed the effects of the variable formula knowledge on the prospective teachers' mathematical-logical structures.

Another measurement tool (hereinafter referred to as measurement tool 3 [MT3]) was designed to determine the effect of the variable basic math knowledge on the prospective teachers' mathematical-logical structures. MT3 contained 50 questions intended to test basic math knowledge. The prospective teachers were provided with a basic mathematical expression and asked to do an operation; that is, to write down the equivalent of the mathematical expression. They were assigned one point if they could provide the correct equivalent. This variable constituted the mathematical procedures for MT1. Each question in MT3 was linked with one or more questions in MT1, as they were based on the basic mathematical operations or basic logical knowledge that the participants had to use to solve the questions in MT1. In this way, an attempt was made to determine whether the participants had basic knowledge about mathematical operations, or basic logical knowledge, to solve the questions in MT1 and to define another variable in their mathematical-logical structures. All the scores assigned to the operations for the questions in MT3 yielded the MT3 score. An association was established between the percentage values of these scores and the ASS and APS scores in MT1, which revealed the effects of the variable basic math knowledge on the prospective teachers' mathematical-logical structures.

One more measurement tool (hereinafter referred to as measurement tool 4 [MT4]) was developed to investigate the effect of the variable scientific knowledge on the prospective teachers' mathematical-logical structures. MT4 had 13 questions about magnetism. The questions were intended to test the participants' procedural and declarative knowledge. Each correct answer was assigned one point. This variable constituted the scientific knowledge procedure for MT1. Each question in MT4 was related to one or more questions in MT1, as the questions in MT4 required the participants to construct scientific knowledge about magnetism to be used to solve the questions in MT1. All the scores obtained from the responses to the questions in MT4 yielded the MT4 score for that question 
in MT1. An association was established between the percentage values of these scores and the ASS and APS scores, which revealed the effects of the variable scientific knowledge on the prospective teachers' mathematical-logical structures.

The data for the present study, which was designed to identify the prospective science teachers' mathematical-logical structures, were analyzed through the VDOIHI, or specifically, its combined stage statistic (Yılmaz, 2011; Yılmaz \& Yalçın, 2011). The data were calculated using the package software program developed for the VDOIHI. Each piece of data was calculated on the basis of a comparison between the score obtained from any stage of the data on the variable and the one expected to be obtained from all stages of the variable (BGS). In this way, the ideal effect of the variable was determined. After each piece of data was calculated separately (calculation for the data on one prospective teacher), all the data were calculated. The calculation of all the data was based on the same principle as the one for each piece; i.e., a comparison was made between the actual scores and ideal scores.

\section{FINDINGS AND INTERPRETATION}

Table 1 presents the calculations based on the scores assigned to the data obtained from four measurement tools administered to 35 prospective teachers in order to reveal their mathematical-logical structures and the variables in their structures.

Table 1: Calculations Based on the Scores Assigned to the Data Obtained from Four Measurement Tools

\begin{tabular}{|l|c|c|c|c|}
\hline \multicolumn{1}{|c|}{ Points/Variable } & Given-Asked & Formula & Operation & Sum of Variables \\
\hline IS(S) & 0.009 & 0.065 & 0.155 & 0.076 \\
\hline APS(S) & 0.132 & 0.283 & 0.197 & 0.204 \\
\hline ANS(S) & -0.021 & -0.078 & -0.116 & -0.072 \\
\hline NAPS(S) & 0.004 & 0.024 & 0.055 & 0.028 \\
\hline SS(S) & 0.834 & 0.550 & 0.477 & 0.620 \\
\hline MT2 & 0.336 & & & \\
\hline MT3 & 0.758 & & & \\
\hline MT4 & 0.199 & & & \\
\hline ASS & 0.305 & & & \\
\hline
\end{tabular}

In Table 1, calculations for the knowledge-level variables are presented separately and calculations for the variables, as a whole, are provided in the last column. The prospective science teachers' achievement level in mathematical logic (ASS) was 0.305. Their knowledge level in mathematical logic (APS) was 0.132 for givenasked, 0.283 for formula, 0.197 for operation, and 0.204 for these variables as a whole, or their general knowledge level (see Table 1). In other words, the prospective teachers' knowledge level in mathematical logic was lower than their achievement level. Furthermore, both their knowledge and achievement levels were rather low.

Table 1 also presents the calculations for given-asked - a knowledge-level variable. The effects of the variable on achievement level were:

- $\quad$ The participants' score/knowledge in the positive stage (APS) positively affected their achievement level (ASS) by $13.2 \%$.

- $\quad$ Their knowledge in the neutral stage (IS) negatively influenced their achievement level by $0.9 \%$.

- $\quad$ Their negative knowledge (ANS) negatively affected their achievement level by $2.1 \%$.

- $\quad$ Their positive knowledge in the negative stages (NAPS) - another type of knowledge in the negative stage had the potential to positively affect their achievement level by $0.4 \%$.

- $\quad$ The zero score (SS), which indicated the level of unknown knowledge for the variable, negatively affected the achievement level by $83.4 \%$.

- $\quad$ The extent to which the variable positively affected the achievement level was equal to the aggregate of the APS and NAPS. In other words, the variable could be argued to positively influence the achievement level by $13.6 \%$. On the other hand, the extent to which the variable negatively affected the achievement level was equal to the aggregate of the IS, ANS, and SS. In other words, the variable could be argued to negatively influence the achievement level by $86.4 \%$. 
Table 1 also presents the calculations for formula - another knowledge-level variable. The effects of the variable on achievement level were:

- The participants' score/knowledge in the positive stage positively affected their achievement level by $28.3 \%$.

- $\quad$ Their knowledge in the neutral stage negatively influenced their achievement level by $6.5 \%$.

- $\quad$ Their negative knowledge negatively affected their achievement level by $7.8 \%$.

- Their positive knowledge in the negative stages, another type of knowledge in the negative stage, had the potential to positively affect their achievement level by $2.4 \%$.

- $\quad$ The zero score, which indicated the level of unknown knowledge for the variable, could negatively affect their achievement level by $55 \%$.

The variable could be argued to positively influence the achievement level by $30.7 \%$, whereas it could be argued to negatively affect their achievement level by $69.3 \%$.

Next, Table 1 presents the calculations for operation - another knowledge-level variable. The effects of the variable on the achievement level were:

- The participants' score/knowledge in the positive stage positively affected their achievement level by $19.7 \%$.

- Their knowledge in the neutral stage negatively influenced their achievement level by $15.5 \%$.

- $\quad$ Their negative knowledge negatively affected their achievement level by $11.6 \%$.

- $\quad$ Their positive knowledge in the negative stages, another type of knowledge in the negative stage, had the potential to positively affect their achievement level by $5.5 \%$.

- The zero score, which indicated the level of unknown knowledge for the variable, negatively affected the achievement level by $47.7 \%$.

The variable could be argued to positively influence the achievement level by $25.2 \%$, whereas it could be argued to negatively affect the achievement level by $74.8 \%$.

The last column in Table 1 presents the calculations for the knowledge-level variables with an influence on the achievement level as a whole. In this way, the overall effect of the knowledge-level variables on the achievement level was evaluated. The extent to which knowledge-level variables could affect achievement level was:

- $\quad$ Knowledge in the positive stage positively affected the achievement level by $20.4 \%$.

- $\quad$ In the neutral stage, it negatively influenced the achievement level by $7.6 \%$.

- $\quad$ The participants' negative knowledge negatively affected their achievement level by $7.2 \%$. Their positive knowledge in the negative stages - another type of knowledge in the negative stage - had the potential to positively affect their achievement level by $2.8 \%$.

- $\quad$ The zero score, which indicated the level of unknown knowledge for the variable, negatively affected the achievement level by $62.0 \%$.

- In addition, the knowledge-level variables positively influenced the participants' achievement level by $23.2 \%$ and negatively influenced it by $76.8 \%$.

These findings indicate a parallel between the APS and NAPS scores, which had a positive effect on the participants' achievement level and the achievement level itself. The IS, ANS, and SS scores, which had the potential to negatively influence achievement level, could be argued to account for the low achievement level.

The procedural variables that collectively affected the prospective science teachers' mathematical-logical structures; i.e., their knowledge and achievement levels (APS and ASS), were identified through MT2, MT3, and MT4. The related calculations are presented in Table 1. The variable formula knowledge (MT2) positively affected the prospective teachers' mathematical-logical structures by $33.6 \%$. Furthermore, the variable basic math knowledge (MT3) positively affected their mathematical-logical structures by $75.8 \%$. Finally, the variable scientific knowledge 
(MT4) positively affected their mathematical-logical structures by $19.9 \%$. These findings revealed the prospective teachers' knowledge and achievement levels in mathematical logic were in parallel with the variables formula knowledge and scientific knowledge. However, the variable basic math knowledge did not have a similar-scale influence on knowledge or achievement levels.

\section{DISCUSSION AND IMPLICATIONS}

The present study concluded that the prospective science teachers had a rather low achievement level (0.305). This must have been caused by the low APS and NAPS scores of given-asked, a knowledge-level variable (13.6\%). The researcher had previously investigated the effect of given-asked, a knowledge-level variable, on prospective science teachers' mathematical-logical structures through a qualitative case study focused on electricityrelated subjects. In that study, the achievement level was 0.30 and the values of the variable given-asked that positively affected the achievement level were $16.0 \%$ (Y1lmaz, 2012). Another qualitative case study had been conducted on the effect of given-asked, a knowledge-level variable, on prospective science teachers' mathematicallogical structures. The study had been focused on subjects associated with Newton's laws of motion. In that study, the achievement level was 0.39 and the values of the variable given-asked that positively affected the achievement level were 3.0\% (Yılmaz \& Yalçın, 2012b, 2012d). Considering the results of the present study and those of other similar studies by the researcher, it can be argued that the reason for the prospective science teachers' rather low achievement level was the low scores related to the variable given-asked. Therefore, it is recommended that prospective teachers' knowledge in the positive stage of the variable given-asked (APS) be increased, whereas their knowledge in the negative and neutral stages should be decreased so that they can have a higher achievement level. It can be concluded that there is a correlation between the variable given-asked and achievement level and that the variable can generate an achievement level that is higher than its own value. Even so, further studies are required to determine the exact correlation between the two.

The values of the variable formula that positively affected achievement level (30.7\% or 0.307) were quite close to the prospective science teachers' actual achievement level (0.305), which suggests that the values of the variable formula that positively affected achievement level might be directly proportional to the achievement level. Different studies can be conducted to identify the correlation more precisely. If a direct link could be identified between the two, prospective science teachers' scientific knowledge (because formula knowledge is closely intertwined with scientific knowledge) could be directly associated with their mathematical-logical structures. Accordingly, it can be argued that the low achievement level found in the present study might have been heavily affected by the values of the variable formula. Modifications in the variable could make significant contributions to enhancing the achievement level.

The values of the variable operation (a knowledge-level variable) positively affected achievement level (APS and NAPS) by $25.2 \%$. This figure was lower than the achievement level, which suggests that the prospective teachers had difficulty carrying out operations and coming up with a result using their existing knowledge. This is also the variable that involves decision-making through operations. The fact that the value of the variable was lower than the achievement level, which actually reflected their right decisions, suggests that the achievement level could be affected by other variables than the knowledge-level variables. These variables were formula knowledge, basic math knowledge, and scientific knowledge for the present study. The values for each variable were 33.6\%, 75.8\%, and $19.9 \%$, respectively. The value of the variable basic math knowledge was high (75.8), which accounts for the fact that the achievement level was higher than the values of operation (a knowledge-level variable) that could affect the achievement level in a positive way. In other words, the value of the achievement level was subtracted from the value of basic math knowledge to yield 0.453 . Next, the values of the variable operation that positively affected the achievement level were subtracted from the achievement level to yield 0.053 . That is, this discrepancy (5.3\% or $0.053)$ must have been caused by the value of the variable basic math knowledge (0.453). Similar findings were revealed through another study by the researcher that investigated the effect of knowledge-level variables and the variables formula knowledge and basic math knowledge on prospective science teachers' mathematical-logical structures, focusing on electricity-related subjects (Yllmaz, 2012). That study yielded the following values: $20.0 \%$ for the values of the variable operation that could affect the achievement level in a positive way, 0.30 for the achievement level, $54.0 \%$ for the variable formula knowledge, and $77.0 \%$ for the variable basic math knowledge. All these findings strongly suggest that the reason the prospective teachers' achievement level was higher than the 
value of operation, the variable involving making decisions and coming up with results, was the discrepancy caused by the variable basic math knowledge. Even so, further studies are required to identify the correlation in a more precise way.

Considering the scores of the prospective teachers for the variables included in MT1, the values that positively affected achievement level collectively affected it by $23.2 \%$. Given that the achievement level was between this figure and the effect of the variable formula knowledge (33.6\%), it is likely that these two variables should be collectively improved so that prospective teachers can see a corresponding improvement in their achievement level in mathematical logic. Similar findings were reported by Yilmaz (2012) who discovered in his study that the achievement level was between these two variables. This study also suggests that the low achievement level was mainly caused by the variable scientific knowledge. In other words, the prospective teachers' poor scientific knowledge about magnetism had an influence on their mathematical-logical structures. Their scientific knowledge was 0.199, whereas their achievement level in mathematical logic was 0.305 , which indicates that their mathematical-logical structures were relatively better and therefore easier to be improved. However, it is another finding of the present study that the variable basic mathematical logic negatively affected this improvement process. Future researchers could focus on this correlation.

After the prospective teachers' knowledge level in mathematical logic was identified through the three variables in MT1, another calculation was made for these variables as a whole and presented in Table 1 as the APS score (0.204). The knowledge level was lower than the achievement level. Three scales with two different contents were used to determine the effects of the variables that could influence the knowledge level in mathematical logic. One of these contents was basic math knowledge, which affected knowledge level in mathematical logic, as revealed through MT3. The findings suggested that the variable had a limited influence on the knowledge level in mathematical logic (Table 1). The effects of two different variables on the prospective teachers' knowledge level were assessed through two different measurement tools designed in reference to the prospective teachers' scientific knowledge about the discipline for which their knowledge level in mathematical logic was identified and the procedural contents for this scientific knowledge. The findings are presented in Table 1 as the results of MT4 and MT2. According to the data on the variables in MT2 and MT4, the prospective teachers' knowledge level in mathematical logic was mainly affected, not by the variable basic mathematical-logical knowledge, but by these two variables. This is not surprising, for one cannot expect the use of logic for knowledge that does not exist. The value of the variable formula knowledge was a little higher than the knowledge level, which suggests that the prospective teachers did not exactly know the logical structure of that knowledge. In addition, the knowledge level was a little higher than the value of the variable scientific knowledge (little, but $65 \%$ on a pro rata basis), which can be accounted for by the effect of the variable basic math knowledge. Therefore, it can be argued that the knowledge level in mathematical logic might have been affected by the interactions between the procedural variables. These results are consistent with those of two other studies by the researcher. In the first study, the researcher discovered that the knowledge level in mathematical logic was 0.16 for the variables as a whole, 0.55 for MT2 and 0.77 for MT3 (Y1lmaz, 2012). In the second one, the knowledge level in mathematical logic was 0.14 and 0.16 for the variables as a whole, 0.54 for MT2, and 0.82 for MT3 (Yılmaz \& Yalçın, 2012b).

The prospective teachers' achievement level (0.305) was higher than their knowledge level (0.204). One reason for this is that the ASS score is judged solely on the basis of the result; i.e., independently of the way the result is reached. This might account for the fact that their achievement level was higher than their knowledge level. However, it cannot explain how the prospective teachers were able to come up with the correct result. The findings of the present study suggest that the cause was the variable basic math knowledge. In other words, it resulted from the value $(0.453)$ being obtained by subtracting the value of the variable basic math knowledge $(0.758)$ from the achievement level (0.305). This value $(0.453)$ was the basic reason the achievement level was higher than the knowledge level by 0.101 .

The results suggest that the prospective science teachers had low levels with regard to their mathematicallogical structures. Even so, their knowledge and achievement levels were higher than their scientific knowledge, which suggests that their mathematical-logical structures were better when compared to their scientific knowledge structures. Are prospective teachers able to learn scientific knowledge or the logical structure of that knowledge in a faster way? How fast can they learn? Is it harder to develop their scientific knowledge structures or mathematical- 
logical structures? These questions may be answered in reference to the effects of changes in the values of the variables. When the development of mathematical-logical structures is considered in terms of the procedural variables, it will apparently be negatively affected, as the teachers had a high value for the variable basic mathematics but a low achievement level. When considered in reference to the knowledge-level variables, their mathematical-logical structures can be developed, if the values for the variables given-asked and operation can be improved. When a comparison is made between the findings of the present study and those of other studies by the researcher (Yılmaz, 2012; Yılmaz \& Yalçı, 2012b) in terms of the effects of the procedural variables on the development of prospective teachers' mathematical-logical structures, the values for the procedural variables seem to have a lower influence on the development of mathematical-logical structures. When the comparison is focused on the knowledge-level variables, it seems that the knowledge-level variables have a higher effect on the development of prospective teachers' mathematical-logical structures.

The prospective teachers' scientific knowledge structures could be interpreted on the basis of formula knowledge and scientific knowledge, two procedural variables in the present study. The value of formula knowledge (MT2) was higher than that of scientific knowledge (MT4) (Table 1), which suggests that formula knowledge can play a key role in attempts to improve prospective teachers' scientific knowledge structures. A comparison between the results of the present study and those of other studies by the researcher on prospective science teachers' scientific knowledge (procedural knowledge and declarative knowledge) structures (Yılmaz \& Yalçın, 2012a, 2012c, 2012d) suggests that the effect of the procedural variables on improving prospective teachers' scientific knowledge structures is almost the same for procedural knowledge but lower for declarative knowledge.

Individuals who are to teach scientific subjects cannot be expected to do so without knowing the logical structures of the knowledge they are to teach. In addition, they are less likely to understand a subject without knowing its logical structure. Therefore, it is recommended that attempts should be made to improve prospective teachers' scientific knowledge structures (mathematical logic), not only for their individual knowledge structures, but also for the educational activities they are expected to lead in the future.

\section{AUTHOR INFORMATION}

Assist. Prof. Dr. İsmail Yilmaz joined the faculty of education at Sakarya University in 2000. He studied for the master program of Sakarya University Science Institute in the 2001-2003 years and the doctoral program of Gazi University Education Sciences Institute in the 2005-2011 years. He has been working as an assistant professor since 2012. His primary research interest is procedural knowledge, declarative knowledge, and mathematical logic in science education. E-mail: iyilmaz@ sakarya.edu.tr

\section{REFERENCES}

1. Bonner, A. J., \& Kifer, M. (1993). Transaction logic: Unifying declarative and procedural knowledge (extended abstract). AAAI Technical Report FS-93-01, 17-25.

2. $\quad$ Gözkan, H. B. (2008). Aritmetiğin Temelleri (pp. 180-185). Istanbul: YKY.

3. Heijenoort, J. (1970). Frege and Gödel two fundamental texts in mathematical logic (pp. 1-2). Cambridge: Harvard University Press.

4. $\quad$ McCarthy, J. (1988). Mathematical logic in artificial intelligence. Daedalus, 117(1), 297-311.

5. Nilsson, N. J., \& Fikes, R. E. (1970). STRIPS: A new approach to the application of theorem proving to problem-solving. Artificial Intelligengence Group, Technical Note 43, SRI Project 8259, Standford Research Institute, California, USA.

6. $\quad$ Özenli, S. (1994). Illim ve teknolojinin olumlu ilkeleri (p. 35). Adana.

7. Ryall, J. (1958). An investigation of the laws of thought (p. 1). New York: Dover Publications.

8. Yılmaz, İ. (2011). Fen bilgisi ögretmen adaylarının Newton'un hareket yasalarını ögrenmelerinde kurallı bilgiden açıklayıcı bilgiye geçişte karşılaştıkları problemlerin incelenmesi. (Unpublished doctor's thesis). Gazi Universitesi, Eğitim Bilimleri Enstitüsü, Ankara (2011), 414012. Retreived from http://tez2.yok.gov.tr/ 
9. Yilmaz, İ. (2012). A study on prospective science teachers' knowledge and achievement levels in mathematical logic in electricity-related subjects. Journal of International Education Research, 8(4), 415424.

10. Yılmaz, İ., \& Yalçın, N. (2011). Probability and possibility calculation statistics for data variables (VDOİHI); statistical methods for combined stage percentage calculation. International Online Journal of Educational Sciences, 3(3), 957-979.

11. Yılmaz, İ., \& Yalçın, N. (2012a). The relationship of procedural and declarative knowledge of science teacher candidates in newton's laws of motion to understanding. American International Journal of Contemporary Research, 2(3), 50-56.

12. Yılmaz, İ., \& Yalçın, N. (2012b). Mathematical logic knowledge of science teacher candidates in newton's laws of motion. International Journal of Applied Science and Technology, 2(3), 99-105.

13. Yılmaz, İ., \& Yalçın, N. (2012c). Prospective science teachers' procedural knowledge about and knowledge control in newton's laws of motion. Sakarya Üniversitesi Ë̆itim Fakültesi Dergisi (SUJEF), 23, 74-99.

14. Yılmaz, İ., \& Yalçın, N. (2012d). The effect of prospective science teachers' achievement levels in procedures and mathematical logic knowledge on their declarative knowledge about Newton's Laws of Motion. Sakarya Üniversitesi Eğitim Fakültesi Dergisi (SUJEF), 23, 121-140. 
NOTES 